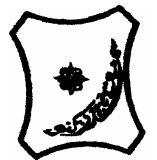

Bayero Journal of Pure and Applied Sciences, 6(2): 6 - 9

Received: July 2013

Accepted: October 2013

ISSN $2006-6996$

\title{
THE INFLUENCE OF SEASON OF BIRTH ON THE PATTERN OF LIP PRINTS IN NIGERIA
}

*Adamu, L. H. ${ }^{1}$ Taura. M. G. ${ }^{1}$ Sadeeq, A. A. ${ }^{2}$ Asuku, A. Y. ${ }^{1}$ Datti, S. ${ }^{1}$ Abdu, I. T. ${ }^{1}$

${ }^{1}$ Department of Anatomy, Faculty of Medicine, Bayero University, Kano, P M B 3011, Kano Nigeria

${ }^{2}$ Department of Human Anatomy, Faculty of Medicine, Ahmadu Bello University, Zaria, Kaduna State, Nigeria *Corresponding author: alhassan.ana@buk.edu.ng/lawanhadamu@yahoo.com

\begin{abstract}
Dermatoglyphs and their components can both environmentally and genetically be determined, even though the arrangement of ridges remains constant throughout life. The aim of this study was to determine the predominant lip print types in different seasons and the influences of the season of birth on the pattern of lip print among Nigerians. Five hundred and six students (256 males and 250 females) were recruited. The lip print was collected using glass slide and developed with carbon black powder. Each print was divided into ten compartments for final analyses of lip prints. Chi-square test was used to test for association between the season of birth and lip prints. Statistical significance was considered at $p<0.05$. The result shows the percentage distribution of lip print in upper lip in wet season with type III (31.02\%) as predominant and type $I^{\prime}(0.29 \%)$ the least, and for dry season the same trend was observed. In lower lip in wet season type $V(29.50 \%)$ was predominant and type $I^{\prime}(0.68 \%)$ the least, and the same trend was observed for dry season. In both lower and upper lips the season of birth shows no statistically significant association (P > 0.05 ) with lip prints in all compartments. In conclusion, the environmental factor considered in this study (season of birth) has no influence in the determination of the lip prints patterns. Hence, recommending the use of lip print as a forensic tool.

Key words; Nigeria, powder, lip prints, season of birth
\end{abstract}

INTRODUCTION

Environmental factors that are present early in life may have an influence on the individual's development. The season of birth as one of environmental factor may contribute equally to the developmental processes during the pre- or perinatal period (Weber et al., 1998). Dermatoglyphs such as lip prints and their components may be environmentally and genetically determined, even though the arrangement of ridges remains constant throughout life (Tsuchihashi, 1974).

The idea of lip prints was first reported by Anthropologist Fischer, and Edmond Locard made the first recommendation on its use as evidence in court of law for personal identity in France (Kasprazak, 1990). Later the idea of using lip print for identification was suggested (Synder, 1950). In the period of 1968-1971 two Japanese Scientists, examined 1364 individuals which led to the conclusion that there is the possibility of using the arrangement of furrows (on a trace. in a linear form) on lips for individual identification. (Suzuki and Tsuchihashi. 1970; Tsuchihashi. 1974). In the study of 76 families with 133 children, 22 mono and 17 dizygote twins in India the lip prints shows uniqueness among the individuals (Hirth et al. 1975). A follow up study for four-months (Vahanwalla and Parekh, 2000), six months (Shilpa et al., 2010), one year (Mahaswari, 2005), five years (Tsuchihashi, 1974) were conducted in order to confirm the consistency as well as influence of environment on the pattern of the lip print.
There are scanty records in literature on the effect of environmental factors especially season of birth on the lip prints pattern in Nigeria. Evaluation of influence of season of birth on lip prints may highlight the reliability of use of lip prints as a forensic tool. The aim of the present study is to determine the predominant lip print types in different seasons and the influence of the season of birth on the pattern of lip prints among Nigerians.

\section{MATERIALS AND METHODS}

The study was conducted among the students of Demonstration secondary school, Ahmadu Bello University, Samaru, Zaria Kaduna State, Nigeria. After informed consent, the data was collected from 506 subjects (256 males and 250 females) aged 12-20 years through the use of questionnaire. All the participants were apparently healthy with absence of external congenital malformation, physical deformities or inflammation. Questionnaire was used in which the sex, date of birth (day/month/year), ethnicity, location of birth and space for placement of glass slide containing lip print. In this study the season of birth was defined as wet season (from April to October) and dry season (from November to March).

The process of collecting the lip print involves placing a clear new microscopic glass slide on the relaxed lips of the subject in a single motion. The glass slide was then removed from the surface of the lip and carbon black powder was poured on the surface of the slide to develop the prints. 
Bajopas Volume 6 Number 2 December, 2013

The glass slide was then placed on an area provided on the questionnaire (with left and right. superior and inferior sides in consideration) (Fig. 1). Finally, a transparent cello tape was used to preserve the print. The print was divided into ten compartments (Adamu et al., 2012). The lip print was classified as type I; a complete vertical group, type I'; a partial length of type I, type II; a branched groove, type III; intersected groove, type IV; reticular, type V: undefined groove (Suzuki and Tsuchihashi. 1970)
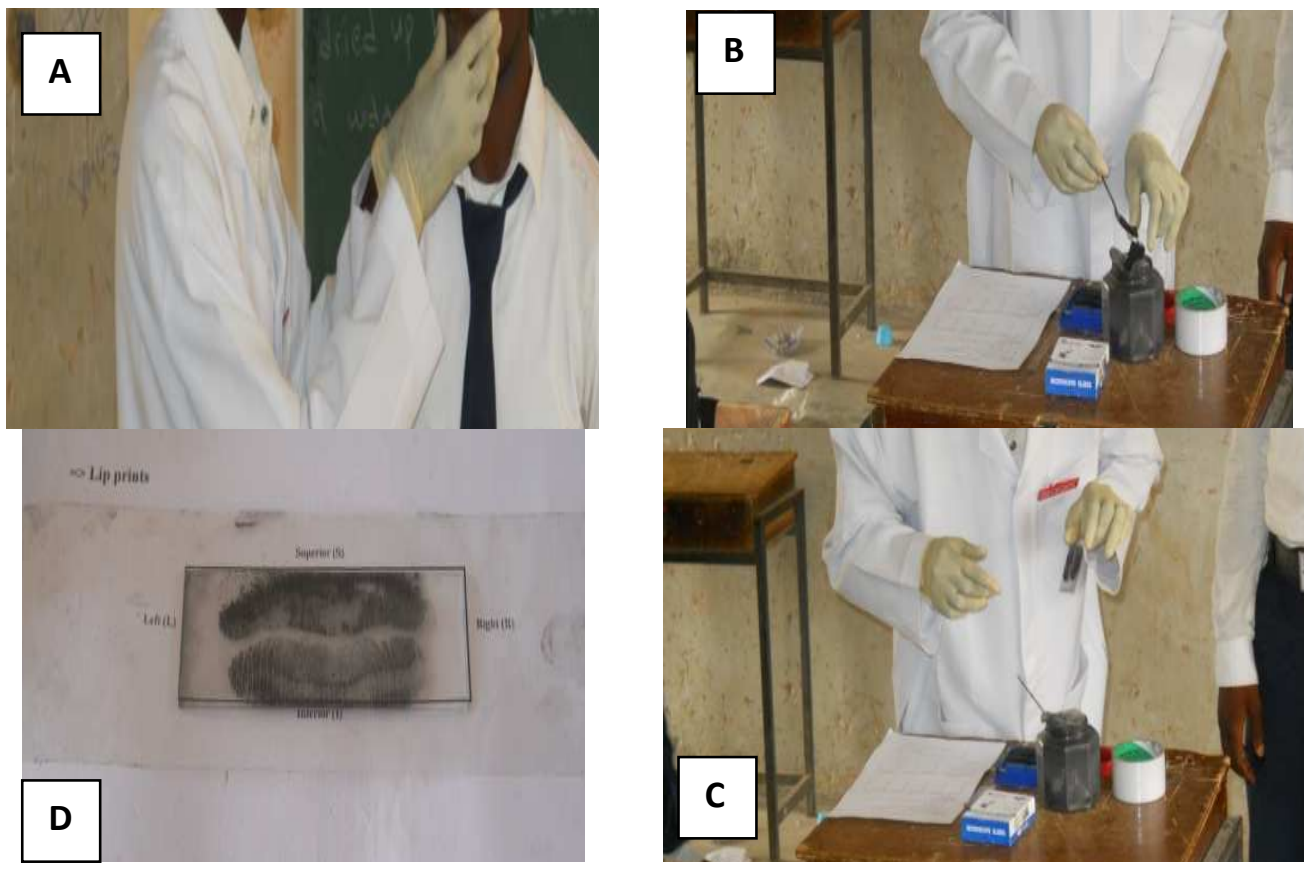

Figure 1: Processes involved in collecting and developing lip prints

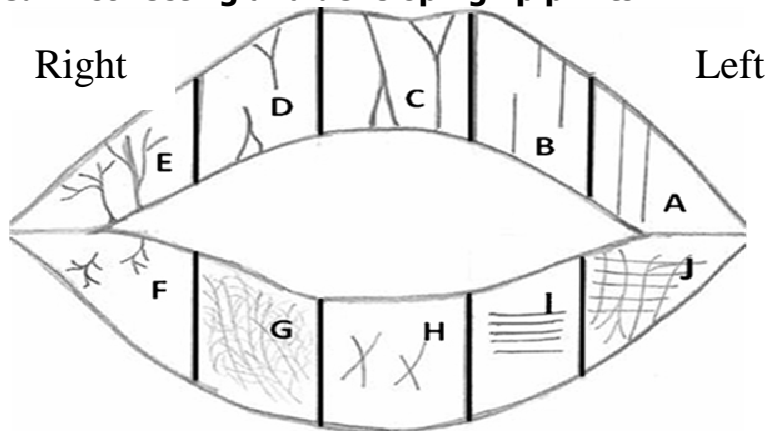

Figure 2: A sketch of lip with ten compartments for estimation of lip prints

Chi-square test was used to test for association between the variables. Statistical significance was considered at $p<0.05$. Analyse it statistical software for Microsoft excel, version, 2.26. 2012 was used for the statistical analysis.

\section{RESULTS}

Table 1 shows the percentage distribution of lip print in upper lip according to season of birth. For wet season type III (31.02\%), was predominant, followed by type V $(28.02 \%)$, type IV $(16.71 \%)$, type I $(14.30 \%)$, type II $(9.66 \%)$ and the least was type I' $(0.29 \%)$. While for dry season type III $(34.58 \%)$ was predominant. followed by type V (26.22\%), type IV $(17.53 \%)$, type I $(13.78 \%)$, type II $(7.56 \%)$ and the least was type $\mathrm{I}^{\prime}(0.33 \%)$. 
Table 1: Percentage distribution of the types of lip prints on upper lip compartments according to seasons of birth

\begin{tabular}{llllllllll}
\hline & \multicolumn{10}{c}{ Lip print types } \\
\hline Compartments & Seasons & I & I' & II & III & IV & V & $\mathbf{X}^{\mathbf{2}}$ & P \\
\hline ULL & Dry & 10.14 & 0.00 & 12.08 & 42.03 & 7.25 & 28.50 & 2.82 & 0.73 \\
& Wet & 11.04 & 0.33 & 8.36 & 45.15 & 6.69 & 28.43 & & \\
& Dry & 13.04 & 0.48 & 12.56 & 30.92 & 17.87 & 25.12 & 4.96 & 0.42 \\
UM & Wet & 14.72 & 0.67 & 9.70 & 36.79 & 19.40 & 18.73 & & \\
& Dry & 23.19 & 0.48 & 2.90 & 12.56 & 31.88 & 28.99 & 4.21 & 0.52 \\
URM & Wet & 20.07 & 0.67 & 5.35 & 10.03 & 37.12 & 26.76 & & \\
\multirow{4}{*}{ URL } & Dry & 14.49 & 0.48 & 9.66 & 32.37 & 17.39 & 25.60 & 4.15 & 0.53 \\
& Wet & 15.05 & 0.00 & 7.69 & 38.80 & 16.39 & 22.07 & & \\
& Dry & 10.63 & 0.00 & 11.11 & 37.20 & 9.18 & 31.88 & 5.04 & 0.28 \\
\hline
\end{tabular}

ULL: upper left lateral, ULM: upper left medial, UM: upper median, URM: upper right medial, URL: upper right lateral

In Table 2 the percentage distribution of lip print in lower lip according to season of birth shows that for wet season type $\mathrm{V}(29.50 \%)$, was predominant followed by type I (19.32\%), type III (19.13\%), type IV $(17.68 \%)$, type II $(13.62 \%)$ and the least was type
$\mathrm{I}^{\prime}(0.68 \%)$. While for dry season type $\mathrm{V}(27.56 \%)$ was predominant, followed by type III $(20.60 \%)$, type IV $(118.99 \%)$, type I $(18.53 \%)$, type II $(14.18 \%)$ and the least was type $I^{\prime}(0.13 \%)$.

Table 2: Percentage distribution of the types of lip prints on lower lip compartments according to season of birth

\begin{tabular}{llllllllll}
\hline & & \multicolumn{10}{c}{ Lip print types } \\
\hline Compartments & Seasons & I & I' & II & III & IV & V & $\mathbf{X}^{\mathbf{2}}$ & P \\
\hline \multirow{2}{*}{ LLL } & Dry & 13.04 & 0.97 & 23.19 & 28.02 & 6.76 & 28.02 & 4.36 & 0.50 \\
& Wet & 10.37 & 0.00 & 22.07 & 30.10 & 8.36 & 29.10 & & \\
& Dry & 21.26 & 0.97 & 12.08 & 15.46 & 24.64 & 25.60 & 8.14 & 0.15 \\
LM & Wet & 18.06 & 0.00 & 15.38 & 22.07 & 21.40 & 23.08 & & \\
& Dry & 30.43 & 0.48 & 2.90 & 6.76 & 29.95 & 29.47 & 5.05 & 0.41 \\
LRM & Wet & 31.77 & 0.67 & 3.01 & 5.02 & 37.12 & 22.41 & & \\
& Dry & 21.74 & 0.48 & 9.66 & 18.36 & 20.77 & 28.99 & 2.36 & 0.80 \\
LRL & Wet & 20.07 & 0.00 & 11.71 & 19.40 & 21.74 & 27.09 & & \\
& Dry & 10.14 & 0.48 & 20.29 & 27.05 & 6.28 & 35.75 & 2.15 & 0.83 \\
\hline
\end{tabular}

LLL: lower left lateral, LLM: lower left medial, LM: lower median, LRM: lower right medial, LRL: lower right lateral

\section{DISCUSSION}

Dermatoglyphs such as lip prints and their components may be environmentally and genetically determined, even though the arrangement of ridges remains constant throughout life (Tsuchihashi, 1974). The influence of season of birth as one of the environmental factor on the lip prints was demonstrated in the present study. The result of the study shows that the season of birth has no significant association with all compartments of the lips (Table 1and 2). This may explain the lack of influence of environmental factors in the determination of the lip prints pattern. This is in agreement with findings of Shilpa et al. (2010) and Tsuchihashi, (1974) which found the consistency of lip prints over period of six months to five years respectively. It was also reported that no change in the lip prints in different periods in the observation of one year (Mahaswari, 2005).

On the other hand the lip prints was used as genetic markers (Afaf et al., 1987). For instance, the hereditary study by Vats et al. (2011) found persistent similarity of lip print pattern among parents and their offsprings but no association was found on lip prints pattern of monozygotic twins. It was reported that there is inheritance of lip prints in cleft lip and cleft plate in children (Weal et al., 2005). The sexual dimorphic trait reported in lip prints were also associated with genetic influences which vary with respect to different sexes more importantly in sex chromosomes (Adamu et al., 2012).

Based on the literature reports genetic factors have marked influence on the lip prints more than the environmental factors. This also gives support for the current finding which shows that season of birth as one of the environmental factors has no effect on the pattern of lip prints. Although, pervious studies revealed the influence of season of birth on other parameters such as birth weight (McGrath et al., 2005), stature (Waldie et al., 2000; McGrath et al., 2006), body-mass index (Phillips and Young, 2000) among others but there is no statistically significant association of season of birth with all compartments of lip prints in both upper and lower lips 


\section{CONCLUSION}

In conclusion, the season of birth is found to have no effect on the lip prints. This may explain the reason of consistency in lip prints over long period of time. Hence, this may add potential to the lip print as a tool

\section{REFERENCES}

Adamu, L.H. Taura, M.G. Hamman, W.O. Ojo, S.A. Dahiru, A.U. Sadeeq, A.A. Ibrahim, A.D. (2012): Association of lip prints and sex among Nigerians. Nigerian Journal of Basic and Clinical Science, 9 (2): 79-83

Afaf, T.Y. Abd-Elwances, S. and El-Awdan, A. (1987): The inheritance of lip prints patterns. Tanta Medical Journal, 1(1): 26

Hirth, L. Gottsche, H. and Goedde, H. W. (1975): Lip prints - variability and genetics. Human Genetic. 30(1): 47-62.

Kasprazak. J. (1990): Possibilities of chieloscopy. Forensic Science International, 46:145-151.

Mahaswari. T. N. U. (2005): lip prints. PG dissertation. Department of oral medicine and Radiology, Saveetha Dental College and hospitals, Chennai

McGrath, J.J. Keeping, D. Saha, S. Chant, D.C. Lieberman, D.E. (2005): Seasonal fluctuations in birth weight and neonatal limb length; does prenatal vitamin D influence neonatal size and shape? Early Human Development, 81: 609-618.

McGrath, J.J. Saha, S. Lieberman, D.E. Buka, S. (2006): Season of birth is associated with anthropometric and neurocognitive outcomes during infancy and childhood in a general population birth cohort. Schizophrenia Research, 81: 91-100.

Phillips, D.I.W. and Young, J.B. (2000): Birth weight, climate at birth and the risk of obesity in adult life. International Journal of Obesity, 24: 281-287.

Shilpa, P. Ish, P. Madhu, S.A. Gayathri, R. and Sowmya, G.V. (2010): A study of lip prints in in solving some issues of personal identity over a long period

\section{Acknowledgement}

We thank all the individuals who volunteered to participate in this research.

relation to gender, family and blood group. International journal of Oral and Maxillofacial pathology, 1(1): 4-7

Suzuku, K. and Tsuchihashi, Y. (1970): A new attempt of personal idenfication by means of lip print. Journal of India Dental Association, 42(1): 89.

Synder, L.M. (1950): Textbook of Homicide investigation. Identification of dead bodies, P. 65

Tsuchihashi, Y. (1974): Studies on Personal Identification by means of lip prints. Forensic Science, 3: 233-284.

Vahanwalla, S.P. and Parekh, D.K. (2000): Study of lip prints as an aid to forensic methodology. Journal of Indian Dental Association, 71: 269-271.

Vats, Y. Dhall, J. K. and Kapoor, A. K. (2011): Heritability of Lip Print Pattern among Northern Indian populations. Journal of Forensic Research, 2: 137.

Waldie, K.E. Poulton, R. Kirk, I.J. and Silva, P.A (2000): The effects of pre- and postnatal sunlight exposure on human growth: evidence from the Southern Hemisphere. Early Human Development, 60: 35-42.

Weal, M. Saad, M. S. Assem, H. K. Hassan, F. Z. and El-otiefy M. A. (2005): Genetic Studies on the Inheritance of Lip Prints in-Cleft Lip and Palate. Egyptian Journal of Plastic Reconstractrive Surgery, 29(1): 9-12

Weber, G. W. Prossinger, H. and Seidler, H. (1998): Height depends on month of birth. Nature 391, $754-755$ 